Disponível em:

http://editora.unoesc.edu.br/index.php/race

Race, Joaçaba, v. 15, n. 1, p. 275-298, jan./abr. 2016

\title{
DETERMINANTES DO PROCESSO DE APRENDIZAGEM NO PROGRAMA TRAINEE DA EMPRESA JÚNIOR DE ADMINISTRAÇÃO (EJA) DA UNIVERSIDADE FEDERAL DA PARAÍBA (UFPB)
}

\section{Determinants of learning process in the Trainee Program of the Management Junior Company (MJC) at Universidade Federal da Paraíba (UFPB)}

Anielson Barbosa Silva

E-mail: anielson@uol.com.br

Doutor em Engenharia de Produção pela Universidade Federal de Santa Catarina; Mestre em Administração pela Universidade Federal da Paraíba; Professor da Universidade Federal da Paraíba. Endereço para correspondência: Cidade Universitária, s/n, Castelo Branco, 58051-900, João Pessoa, Paraíba, Brasil.

Vinicius Paiva Costa

E-mail: pcosta.vinicius@gmail.com Graduado em Administração pela Universidade Federal da Paraíba.

Saulo Oliveira Monteiro Dias

E-mail: saulo.monteiro.dias@gmail.com Graduado em Administração pela Universidade Federal da Paraíba.

Artigo recebido em 26 de junho de 2015. Aceito em 14 de outubro de 2015. 


\title{
Resumo
}

Neste estudo objetivou-se analisar os determinantes do processo de aprendizagem dos participantes do Programa Trainee da Empresa Júnior de Administração (EJA) da Universidade Federal da Paraíba (UFPB). A pesquisa, de caráter exploratório, configura-se como um estudo de caso qualitativo. Os dados foram coletados por meio de entrevistas com ex-participantes do Programa. Os resultados subsidiaram a identificação da estrutura do Programa Trainee da EJA, bem como os fatores facilitadores e limitantes do processo de aprendizagem dos Trainees. O Programa contribui para a formação profissional dos alunos, mas o volume de atividades e o nível de cobrança exagerados em alguns momentos podem afastar bons talentos da empresa. Participar de uma empresa júnior e interagir com o Movimento de Empresas Juniores durante a graduação pode ser enriquecedor ao proporcionar amadurecimento pessoal e profissional, além de orientar os alunos em relação aos rumos futuros de suas carreiras. Por outro lado, é preciso prudência para que o aluno não coloque a vivência na empresa júnior em nível de importância superior à formação acadêmica, uma vez que a integração entre teoria e prática, quando bem articulada, é determinante na carreira do administrador.

Palavras-chave: Aprendizagem. Programa trainee. Competências. Empresa júnior. Administrador.

\section{Determinants of learning process in the Trainee Program of the Management Junior Company (MJC) at Universidade Federal da Paraíba (UFPB)}

\begin{abstract}
This study aimed to analyze the determinants of learning process of participants in the Trainee Program of the Management Junior Company (MJC) of Universidade Federal da Paraíba (UFPB). The research was classified as exploratory and is configured as a qualitative case study. The data were collected through interviews with alumni that participated of the Program. The results revealed the identification of the structure of the Trainee Program of the MJC, as well as facilitators and limiting factors of the Trainees learning process. The Trainee Program contributes to the professional training of students, but the excessive volume of activities and level of demand at times can move away good talents from the company. Participating of a junior company and interacting with the movement of Junior Companies during graduation can be enriching to provide personal and professional maturity, in addition to guiding the students in relation to the future direction of their careers. On the other hand, we need caution so that the student does not place the experience in junior company in a highest level of importance in relation to academic education, once the integration between theory and practice, when wellarticulated, is crucial in the career of the administrator.
\end{abstract}

Keywords: Learning. Trainee program. Competence. Junior company. Administrator. 


\section{INTRODUÇÃO}

As constantes mudanças no cenário competitivo e, consequentemente, no ambiente interno das organizações demandam a participação mais efetiva das pessoas, o que requer melhores níveis de capacitação e qualificação profissional (BITTENCOURT, 2002). Para Araújo et al. (2007), a importância dos programas de capacitação executiva cresceu em virtude da percepção do valor competitivo do capital humano para as organizações, principalmente dos gestores que precisam planejar, organizar, dirigir e controlar e acabam tendo o destino do negócio em suas mãos. Uma das maneiras mais eficazes de se prover quadros funcionais com pessoas de alto potencial produtivo, visando à conversão de suas capacidades profissionais em resultado para as organizações, são os Programas Trainees (MARTINS, 2008).

Fatores como a diferenciação intelectual, a valorização do talento e das aptidões profissionais e o foco na qualificação têm levado as empresas a investirem na captação de jovens com o novo perfil desejado por meio desses programas de treinamento, que buscam o desenvolvimento de competências visando à qualificação para que, em curto e médio prazos, os treinandos assumam posições de liderança. Por se tratarem de processos de treinamento e capacitação de futuros líderes, é necessário que, ao se estudarem Programas Trainees, também seja considerando o processo de aprendizagem dos indivíduos participantes, que se submetem a inúmeras influências, pressões e estímulos do contexto, que podem se refletir positiva ou negativamente na maneira como assimilam o conhecimento transmitido.

Sabe-se, contudo, que a aprendizagem é uma temática abrangente e que pode ser estudada sob diversas perspectivas e níveis de análise. Neste estudo, aborda-se a aprendizagem em nível gerencial (FOX, 1997). Silva (2009) sugere que a aprendizagem dos gerentes é multidimensional por abranger duas dimensões da prática gerencial: a objetiva e a subjetiva. Na primeira, a aprendizagem ocorre por meio de ações formais, voltadas para a transmissão de conhecimento técnico e desenvolvimento de competências que levam à formulação e implementação de estratégias em áreas como produção, marketing, recursos humanos e finanças. Há, ainda, a orientação para a prática gerencial, com foco no aprimoramento de aptidões executivas como relacionamento com pares, superiores e subordinados, visão sistêmica, negociação, trabalho em equipe, técnicas de apoio à tomada de decisão, entre outros. Por outro lado, a dimensão subjetiva refere-se ao lado interior de cada pessoa, a busca pelo autoconhecimento, a reflexão sobre experiências vividas, sensações, medos e traumas pessoais, 
que também contribuem para a aprendizagem e, muitas vezes, não são devidamente abordados no discurso gerencial.

O processo de aprendizagem gerencial também pode ser analisado a partir da perspectiva de aprendizagem social e contribuir para ampliar o nível de compreensão sobre o contexto e os fatores que influenciam a aprendizagem. Uma das ações de desenvolvimento de novos gestores para as organizações envolve os Programas Trainees. Esses programas foram concebidos para selecionar profissionais pouco experientes, geralmente recém-formados, e desenvolver um conjunto de competências gerenciais.

Neste estudo, objetiva-se analisar os determinantes do processo de aprendizagem no Programa Trainee da Empresa Júnior de Administração (EJA) da Universidade Federal da Paraíba (UFPB).

\section{FUNDAMENTAÇÃO TEÓRICA}

A literatura traz várias definições sobre os Programas Trainees. Godoi et al. (2008) afirmam que os programas trainees auxiliam no desenvolvimento da carreira de pessoas com alto potencial para atuarem em posições estratégicas nas organizações. A origem da palavra trainee está associada ao termo inglês training, que significa treinamento. Os Programas Trainees gradativamente se desenham como uma poderosa ferramenta de enriquecimento planejado do capital humano para as grandes organizações (ARAÚJO, 2004), já que formam profissionais extremamente capacitados para assumirem posições gerenciais de médio a longo prazo. Todo o investimento empreendido no desenvolvimento dos participantes retorna em forma de conhecimento para a própria organização.

Para Martins (2008), os Programas Trainees são programas estruturados que objetivam a capacitação de pessoas de alto nível recém-egressas do ensino superior para seu desenvolvimento e socialização. Em suma, consistem em processos de seleção e treinamento de jovens recém-graduados, com duração que varia, geralmente, de seis a dezoito meses, voltados para formar e capacitar futuros líderes das organizações.

Luz (1999) vai além ao afirmar que não são necessárias aos candidatos apenas competências técnicas, mas também características específicas de personalidade e comportamento, como gosto por desafios, interesse em aprender, bom relacionamento interpessoal, criatividade, ambição, foco no cliente e nos resultados, visão estratégica e saber trabalhar sob pressão e em equipe.

Os programas Trainees são caracterizados pelo alto nível de exigência e cobrança dos candidatos, que lidam com situações diárias de pressão e estresse diárias ao longo do processo. São atrativos, contudo, pelas vantagens oferecidas, que vão 
desde assistência médica integral a auxílios especiais, e pela boa remuneração, geralmente, acima da média do mercado. Por serem demasiadamente longos e desgastantes emocionalmente, os índices de desistência são acentuados, o que configura um grande risco às organizações, que investem quantias consideráveis para assegurarem a qualidade do projeto e nem sempre obtêm o retorno esperado.

Ao final do período de treinamento, os trainees são efetivados pela empresa e alocados em áreas compatíveis com o perfil e as competências demonstradas ao longo do processo. A fase de adaptação do novo membro, contudo, pode ser problemática tanto para o ex-trainee quanto para a organização. Frequentemente, as empresas não fazem jus aos grandes investimentos empregados na capacitação dos candidatos, atribuindo-lhes tarefas obscuras, o que leva muitos a abandonarem seus postos por não terem suas expectativas concretizadas (GONTIJO; MELO, 2005). A participação em um programa trainee pode contribuir para o desenvolvimento gerencial, uma vez que oportuniza a vivência de experiências e pode potencializar a aprendizagem.

\subsection{O PROCESSO DE APRENDIZAGEM DE GERENTES NO CONTEXTO DO PROGRAMA TRAINEE}

De modo geral, o processo de aprendizagem pode ser definido como a maneira pela qual os seres humanos adquirem e assimilam novos conhecimentos, desenvolvem competências e alteram seu comportamento (ZEFERINO; PASSERI, 2007). A aprendizagem envolve, basicamente, a troca de interações entre o indivíduo e o meio social no qual está inserido. Constitui o processo pelo qual se adquire a competência e, nesse contexto, é fundamental a vivência de experiências, que darão margem para o desenvolvimento de crenças, insights, conhecimento, objetivos e metas. Em suma, o indivíduo processa mentalmente uma informação decorrente de uma experiência vivida, atribui-lhe um sentido cognitivo e passa a incorporar o entendimento resultante ao seu comportamento. Pelo fato de cada ser humano possuir uma essência cognitiva própria, pode-se afirmar que o processo de aprendizagem ocorre de diferentes maneiras, ritmos e aspectos, de acordo com cada pessoa. Ou seja, cada ser humano aprende de uma maneira singular. Para Kim (1993), aprender significa adquirir novas condutas ou modificar condutas já existentes. Complementando o raciocínio desse autor, Le Boterf (2003) acredita que as competências são originadas a partir de três eixos bem definidos: as interações sociais do indivíduo, sua formação acadêmica e suas experiências profissionais. Este último ponto remete ao conceito da aprendizagem-ação, o qual compreende que o aprendizado é consequência da prática sistemática vivenciada pelo indivíduo no dia a dia da organização. 
A aprendizagem em nível gerencial surge para suprir um gap entre a educação e o processo de desenvolvimento gerencial (FOX, 1997). Embora ainda incipientes no Brasil, as pesquisas que envolvem a aprendizagem gerencial têm contribuído para o desenvolvimento de sistemas mais efetivos que auxiliem os executivos no processo de aprendizado (MORAES; SILVA; CUNHA, 2004). A aprendizagem gerencial em sua abordagem tradicionalista, segundo Fox (1997), não ocorre apenas por meio do desenvolvimento ou da educação gerencial, mas também no dia a dia do trabalho; por isso, pesquisa e prática nessa área devem envolver os três domínios - educação, desenvolvimento gerencial e contexto da prática.

A aprendizagem gerencial é resultado da maneira como ocorre a transmissão do conhecimento técnico (dimensão objetiva) que, por sua vez, é moldada e varia de acordo com a cognição de cada indivíduo, suas experiências pessoais, traumas, valores e crenças consolidados ao longo de sua vivência (dimensão subjetiva). Quando se trata de Programas Trainees, os receptores do conhecimento, em sua maioria, são jovens recém-graduados e com a personalidade em formação, o que pode potencializar os efeitos do contexto social na consumação da aprendizagem, já que estes estão muito mais sujeitos a influências externas, dada a pouca experiência de vida.

Os futuros gerentes passam por um processo de seleção rigoroso e recebem treinamento formal na organização, são acompanhados por gestores mais experientes e desenvolvem atividades ao longo de determinado período de tempo. Vários profissionais que participam de um Programa Trainee enfrentam dificuldades e acabam se frustrando em relação ao processo. Após a realização de uma pesquisa para analisar a relação entre cultura organizacional e identidade de jovens executivos trainees de uma organização multinacional, Toledo e Bulgacov (2004) constataram que os jovens participantes vivenciam o sofrimento, que vai desde o processo seletivo até as frustrações pós-programas, decorrentes da incompatibilidade entre as expectativas iniciais e a realidade, uma vez que o jovem trainee precisa se ajustar à cultura organizacional e enfrenta situações adversas decorrentes da “[...] falta de alinhamento entre as diretrizes de RH e os outros setores, relativamente ao recebimento dos participantes do programa.” (TOLEDO; BULGACOV, 2004, p. 13).

Os participantes de um Programa Trainee sofrem a influência do contexto social, o que indica a necessidade de se aprofundarem os estudos sobre o papel deste na aprendizagem de jovens que participam de programas de desenvolvimento como o de trainees. Não adianta promover uma seleção rigorosa se o contexto da organização não for preparado para ajudar no desenvolvimento gerencial por meio de processos 
de aprendizagem, sejam eles formais ou decorrentes da troca de experiências e da reflexão no contexto da ação profissional.

Essa perspectiva de aprendizagem insere aspectos que podem ajudar a compreender as dificuldades e os desafios enfrentados por um trainee no processo de socialização e legitimação. Como afirmam Lave e Wenger (1991), a legitimação é uma característica determinante para entender a maneira de pertencer a um contexto social. Gherardi, Nicolini e Odella (1998) consideram que um aprendiz passa por vários estágios dentro de uma organização. Quando é inserido no contexto, é considerado um novato; depois, passa a ser um iniciante avançado, um aprendiz competente e um aprendiz expert. Esse cenário de desenvolvimento depende de um processo denominado por Lave e Wenger (1991) de participação periférica legitimada, que subsidia o desenvolvimento de um currículo situado, grupos de atividades que somente são aprendidas pelos participantes se estes forem legitimados como membros do contexto social.

\subsection{O PAPEL DA EMPRESA JÚNIOR NA APRENDIZAGEM}

A discussão sobre o excesso de teoria em detrimento à falta de prática no ensino superior é recorrente e polêmica (COSTA; SILVA, 2011). O fato é que os conhecimentos adquiridos na sala de aula e por meio de livros e atividades curriculares não são suficientes para a preparação de profissionais qualificados. No mercado de trabalho contemporâneo, não há espaço para recém-formados sem conhecimentos complementares à sua área de atuação, sem diferenciação em relação aos demais e, principalmente, sem histórico de experiências com a prática. As chamadas empresas juniores são entidades sem fins lucrativos, formadas e geridas por alunos do ensino superior e idealizadas com o intuito de solucionar o gap entre teoria e prática observado na maioria dos cursos de graduação.

Os estudantes têm a oportunidade de estar em contato com o mercado de trabalho, prestando serviços que vão desde consultoria e assessoria até a comercialização de sistemas de informação e adquirindo conhecimentos e experiências que lhes serão úteis para sua formação profissional. Os processos seletivos das empresas juniores, em linhas gerais, são bem organizados e se equiparam aos adotados por uma empresa comum. Muitas delas, inclusive, apresentam Programas Trainees estruturados para a captação de seus membros.

As empresas juniores traduzem um caminho inverso da lógica da produção de conhecimento em universidades, uma vez que geram aprendizados tanto acadêmicos quanto mercadológicos de maneira simultânea, enquanto, normalmente, busca-se aplicar a teoria aprendida à prática do mercado de trabalho (SÁ; OLIVEIRA; HONÓ- 
RIO, 2005). O Movimento de Empresas Juniores (MEJ) é de origem francesa e surgiu na década de 1960, tendo se expandido rapidamente por todo o mundo (BRASIL JÚNIOR, 2010). Os alunos executam os projetos sob a orientação dos professores, o que torna o aprendizado mais preciso e garante a qualidade dos produtos finais. Apesar de sua importância e suas contribuições, as empresas juniores constituem um espaço de aprendizagem ainda pouco explorado pelas Instituições de Ensino Superior (ANDRADE, 2009).

\section{PROCEDIMENTOS METODOLÓGICOS}

O estudo pode ser classificado como uma pesquisa qualitativa de natureza exploratória e foi realizada com 15 ex-participantes do Programa Trainee da Empresa Júnior de Administração (EJA) da Universidade Federal da Paraíba (UFPB), definidos a partir de levantamento do histórico dos programas realizados desde o ano de criação do Programa (1993). Os sujeitos da pesquisa foram definidos de forma não probabilística de acordo com a disponibilidade dos entrevistados.

A coleta dos dados foi realizada por meio de entrevista baseada em roteiro semiestruturado. Os dados coletados foram gravados e transcritos na íntegra. O perfil dos participantes do estudo envolve pessoas de 20 a 27 anos de ambos os sexos, sendo oito homens e sete mulheres. Para garantir a diversidade dos sujeitos pesquisados, optou-se por entrevistar ex-participantes que ingressaram no Programa em cinco anos diferentes. Essa diversificação, além de inibir uma possível análise tendenciosa dos dados, favoreceu o delineamento de um paralelo de evolução da estrutura do Programa ao longo de cada edição, de acordo com as percepções coletadas nas entrevistas.

Após a transcrição integral das entrevistas, os depoimentos foram codificados para fins de identificação por meio da nomenclatura “TrN.n”, na qual "Tr” e "N" simbolizam o entrevistado, e "n”, o número do discurso de acordo com a codificação. Os depoimentos codificados foram agrupados em categorias que subsidiaram a etapa de análise e discussão de resultados do estudo. A análise dos dados seguiu as orientações propostas por Silva (2010), envolvendo a identificação de temas, a delimitação de categorias vinculadas ao tema e a análise dos discursos dos entrevistados. Os resultados da pesquisa são apresentados na próxima seção.

\section{RESULTADOS DA PESQUISA}

Os resultados obtidos a partir da transcrição das entrevistas foram categorizados para viabilizar o tratamento das informações, de acordo com a seguinte clas- 
sificação: estrutura do Programa Trainee, aspectos facilitadores da aprendizagem e aspectos limitadores da aprendizagem.

\subsection{O PROGRAMA TRAINEE DA EJA}

A Empresa Júnior de Administração (EJA/UFPB) é uma associação civil sem fins lucrativos, formada e gerida por alunos do Curso de Administração. Fundada em 1991, é a EJA mais antiga da Paraíba e atua no ramo de consultoria em gestão, oferecendo em seu portfólio serviços como Pesquisa de Mercado, Planejamento Estratégico, Programa 8s, Mapeamento de Processos e Plano de Marketing, além de projetos customizados. Sua estrutura é matricial e composta por cinco departamentos: Marketing, Administrativo-Financeiro, Recursos Humanos, Projetos e Qualidade, que atuam em sintonia com a Diretoria Presidente e o Conselho Consultivo, formado por três ex-membros escolhidos por meio de votação.

O Programa Trainee da EJA foi instituído no ano 2001 com o objetivo de reduzir os impactos provocados pelos altos índices de rotatividade dos membros e pela falta de legitimidade das práticas de admissão utilizadas na época. Inicialmente, foi implementado de forma experimental, tendo duração de 45 dias e participação restrita aos diretores da empresa.

Os registros apontam que, nas 12 edições realizadas até o presente estudo, 250 alunos do Curso de Administração da UFPB foram recrutados, sendo 194 selecionados para o Programa Trainee. Desse total, 112 candidatos foram efetivados ao final do processo, representando um índice de aproveitamento de, aproximadamente, 58\%. Estima-se que o índice de desistência do programa, que é considerado rigoroso e desgastante, gire em torno de 35\% do total de selecionados em cada edição, realizada duas vezes por ano. Ao todo, 68 membros que passaram pela EJA já saíram encaminhados ao mercado de trabalho.

Os dados foram resgatados do arquivo da empresa sob a autorização e supervisão dos responsáveis, que garantiram a legitimidade dos dados compilados na pesquisa.

\subsection{FATORES FACILITADORES DA APRENDIZAGEM NO PROGRAMA TRAINEE DA EJA}

Nesta seção buscou-se analisar a opinião dos entrevistados quanto aos fatores que facilitam o processo de aprendizagem no Programa Trainee da EJA. A análise dos dados revelou a existência de três fatores facilitadores: relacionamento interpessoal, nível de exigência e aprendizado com base na ação. 


\subsubsection{Relacionamento interpessoal}

No caso do Programa Trainee da EJA, os resultados da pesquisa revelaram que o relacionamento dos participantes com os demais integrantes de sua equipe e, até mesmo, com os membros da empresa foi fundamental tanto para o desenvolvimento quanto para a superação das dificuldades inerentes ao processo de aprendizagem. A própria estrutura do Programa, ao favorecer a realização de atividades em grupo, fez com que os laços entre os participantes se fortalecessem, o que auxiliou, significativamente, o desempenho individual dos trainees e a sua postura em sala de aula durante os treinamentos.

Os trainees XIII e XIV, quando perguntados sobre os principais fatores que contribuíram para o seu aprendizado durante o Programa Trainee da EJA, destacam a importância da estrutura voltada para a interação e o trabalho em equipe. É o que se constata ao falarem: "Eu não tenho dúvidas de que o que fez a minha performance ficar boa foi o trabalho em equipe” (TrXIII.7, informação verbal, griso nosso) e “Acho que foi o trabalho em equipe. A gente conseguia se integrar e produzir juntos, meus colegas, a gente se juntava pra trabalhar nas madrugadas e individualmente, incentivo que um dava ao outro. A gente conseguia se completar” (TrXIV.9, informação verbal, grifo nosso).

Além do contato com os membros da equipe do plano de negócios, os trainees também desenvolviam atividades com os demais participantes do Programa, já que após cada aula eram realizadas dinâmicas para fixação do conteúdo, e as equipes eram determinadas aleatoriamente, para que todos trabalhassem juntos em algum momento. A possibilidade de trabalhar com outras pessoas foi uma ideia aprovada pelos trainees, mas nem sempre o trabalho em equipe nessas condições foi uma experiência agradável como nos exemplos citados anteriormente. O trainee III relata a sua experiência de trabalhar com uma pessoa conflituosa ao dizer:

Eu acho que uma coisa que contribuiu muito foi um certo problema que eu tive dentro do Programa, que foi trabalhar com uma pessoa totalmente diferente de mim, e que trazia problemas que eu, a princípio, não sabia resolver. A partir dessa experiência, a gente aprendeu a lidar com essas situações, como saber lidar em grupo, como saber respeitar a opinião de cada um e saber desenvolver o meu trabalho tanto em grupo quanto sozinha a partir dessas dificuldades. (TrIII.7, informação verbal, grifo nosso).

Nem sempre as experiências de trabalho em equipe serão positivas, mas isso não significa que não se pode tirar uma lição positiva dessas situações. No caso ex- 
posto, apesar de o trainee relatar as dificuldades de trabalhar com uma pessoa de perfil diferente do seu, reconhece a importância de ter aprendido a lidar com isso e avalia que o relacionamento contribuiu de forma positiva para o seu crescimento durante o Programa. Essa afirmação também evidencia que o aprendizado não ocorre apenas em situações favoráveis, mas também a partir de conflitos, que geram reflexão e, consequentemente, conhecimento.

Outro aspecto ligado ao relacionamento entre os participantes do Programa é o senso de cooperação. Apesar de estarem em um processo seletivo baseado na concorrência, no qual apenas os melhores sobrevivem, os trainees afirmaram não haver um nível de competitividade acentuado, sobretudo pelo fato de não existir um limite de vagas por edição. Assim, apesar de a atmosfera do Programa estar voltada para que os participantes se destaquem demonstrando suas competências, havia boa relação com as demais equipes.

O senso de cooperação apontado pelos entrevistados é mais um indício de que o relacionamento interpessoal no Programa Trainee da EJA é um fator positivo para o processo de aprendizagem dos participantes. Nesse sentido, saber que todos os que forem competentes serão aprovados, não havendo um número de vagas específico, facilita o entrosamento entre eles.

Pode-se constatar, a partir da análise dos dados, que o trabalho em equipe favorece o relacionamento interpessoal entre os participantes e, consequentemente, o processo de aprendizagem, que ocorre tanto no ambiente da sala de aula quanto nas ocasiões em que os membros se reúnem para desenvolver as atividades em horários alternativos. $\mathrm{O}$ aprendizado em linhas gerais é oriundo de experiências positivas, mas os depoimentos também evidenciaram a contribuição dos conflitos entre os participantes para o processo de assimilação do conhecimento e crescimento profissional.

\subsubsection{Nível de exigência}

O Programa Trainee da EJA é tido como um dos mais rígidos entre as empresas juniores. Com duração que varia de dois a três meses, coloca à prova a disposição dos participantes de lidarem com pressões constantes, em situações que simulam intencionalmente a realidade do mercado. Quando questionados se o Programa está de acordo com a realidade, apesar de reconhecerem a dificuldade e de discordarem de algumas posturas consideradas desproporcionais, os trainees são conscientes de que as práticas adotadas no Programa estão de acordo com o que é vigente no mercado profissional atualmente, como pode ser constatado pelo discurso: "Eu acho que corresponde sim, a cobrança, algumas atividades, eu acho que corresponde. Mas talvez o 
comportamento de algumas pessoas não correspondia. Muitas pessoas que cobravam maturidade também não tinham.” (TrVI.24, informação verbal, grifo nosso).

Corroborando Gontijo e Melo (2005), a cobrança e o foco no desempenho é uma realidade tida como regra dos Programas Trainees. Em termos de compatibilidade, é coerente a conclusão de que a estrutura rígida do Programa está de acordo com o mercado.

Por outro lado, a citação "Olha, eu acho que corresponde sim, mas a forma que a EJA cobra é diferente da forma do mercado. Mas aqui eu entendi, a gente precisa ter um pouco mais de rigidez, exatamente porque não ganha dinheiro, então muitas vezes a gente leva 'nas coxas’ o programa.” (TrXV.25, informação verbal, grifo nosso). O participante adota uma perspectiva diferente ao analisar a rigidez do Programa e a ausência de remunerações pelo trabalho. Segundo ele, as cobranças do Programa são positivas, pois além de corresponderem às práticas de empresas seniores, despertam nos participantes o desejo e a motivação necessários para fazer parte da EJA mesmo não recebendo dinheiro por isso. Os resultados do estudo indicam que as cobranças, apesar de em um primeiro momento parecerem negativas, em proporções aceitáveis, são benéficas para os trainees, pois simulam a realidade mercadológica e atuam como um mecanismo de retenção dos talentos ao despertarem a curiosidade dos participantes.

Em relação às contribuições voltadas para o processo de aprendizagem, é interessante notar que, de acordo com o ponto de vista dos participantes, as cobranças foram fundamentais para o seu amadurecimento pessoal e profissional, como revela o depoimento: "Eu sabia que realmente aquilo ia ter uma implicação grande pra o meu futuro e agora eu realmente vejo a importância.” (TrXV.22, informação verbal, grifo nosso).

Os trainees reconhecem que a política de feedbacks constantes e, até mesmo, as repreensões são importantes para que novas competências sejam desenvolvidas ou aprimoradas. A vontade dos participantes de se capacitar, quando superior aos obstáculos, pode transformá-los em degraus para a aprendizagem e o desenvolvimento de competências. Os discursos: “Como eu queria me capacitar o mais rápido possível dentro do curso, e o objetivo do trainee é exatamente esse, acho que não teve nenhum tipo de conflito. Alinhou direitinho ao que eu pensava, ao que queria, e aos objetivos do Programa” (TrV.22, informação verbal, grifo nosso) e

Não, assim... É lógico que a gente não estava acostumado ao nível de exigência que foi apresentado ao longo do programa, né? Mas ao mesmo tempo, se era aquilo que eu já esperava, então $a$ gente tinha que se adaptar, independente se era difícil ou fácil. (informação verbal, grifo nosso). 
Era um dos meus objetivos: se capacitar (TrV.23, informação verbal, grifo nosso). Desse modo, a rigidez assume uma faceta positiva, pois faz com que os trainees se mantenham alertas durante o Programa e filtrem as experiências negativas, consolidando-as em aprendizado após um processo reflexivo.

A seguir, são analisados os impactos positivos da metodologia baseada na aprendizagem em ação adotada pelo Programa Trainee da EJA.

\subsubsection{Aprendizagem com base na ação}

A Empresa Júnior de Administração adota em seu Programa Trainee uma estrutura de capacitação baseada em atividades práticas (SÁ; OLIVEIRA; HONÓRIO, 2005). Essa estratégia, como abordado em passagens anteriores, é necessária porque os participantes, geralmente, estão cursando fases iniciais da graduação e não possuem competências profissionais bem desenvolvidas. Assim, as simulações práticas possibilitam aos trainees que vivenciem antecipadamente as situações que encontrarão no mercado. Citações como "No trainee, desde a seleção até o final, a gente passou por dinâmicas de grupo, testes individuais, a gente passava por apresentações de propostas de serviços [...] Bem como a atividade final que norteou todo o trainee, que foi o plano de negócios” (TrIII.8, informação verbal, grifo nosso) corroboram essas afirmações.

Todas as atividades práticas do Programa eram precedidas por aulas teóricas. Assim, os participantes assimilavam o conteúdo para, em seguida, aplicá-lo em atividades como seminários e dinâmicas de grupo. Quando perguntados sobre os principais fatores que contribuíram com o processo de aprendizagem ao longo do Trainee, grande parte dos entrevistados elogiou a estrutura voltada para a prática e atribuiu a esta parcela relevante do conhecimento gerado, como destaca o discurso "Na verdade, eu acho bom esse método de aulas e dinâmicas que incentivam a pessoa a praticar o que aprendeu naquela aula. Você tem aulas e tem dinâmicas, e você acaba praticando o que acabou de aprender. E isso faz com que você grave, entenda, tire as dúvidas, essas coisas." (TrII.3, informação verbal, grifo nosso). Fica evidente o papel positivo das atividades práticas no processo de formação do participante. De acordo com o trainee, as simulações reforçam o aprendizado e estimulam a geração de um ambiente favorável à discussão e resolução de dúvidas.

A aprendizagem em ação no Programa da empresa também é estimulada por meio de atividades em grupo. Respostas como "O que contribuiu mais para o meu aprendizado foi o plano de negócios em si. [...] então, essa mistura de aprender, de colocar em prática o lado técnico, conseguir ter a desenvoltura de lidar com esse 
grupo diferente, foi o que eu aprendi mais” (TrVI.6, informação verbal, grifo nosso) reforçam que a maioria das ações, desde os seminários até as dinâmicas de grupo, privilegiam o trabalho em equipe e a capacidade de resolução dos problemas com base no esforço coletivo. Segundo alguns depoimentos, pensar em grupo faz bem e contribui para o aprendizado.

No contexto do Programa, aprender por meio da ação pode ser um bom caminho a ser seguido, agregando valor profissional aos participantes. Na seção seguinte são analisados os aspectos que limitam o processo de aprendizagem no Programa Trainee da EJA.

\subsection{FATORES LIMITANTES DA APRENDIZAGEM NO PROGRAMA TRAINEE DA EJA}

Apesar dos facilitadores da aprendizagem destacados na seção anterior, os depoimentos também revelaram que em algumas situações o Programa Trainee da EJA possui características que interferem negativamente no processo de assimilação do conhecimento. Dificuldade de conciliação com a rotina, conflitos comportamentais e ideológicos e as pressões do contexto social foram, de acordo com os entrevistados, algumas das dificuldades que mais afetaram o seu desempenho.

\subsubsection{Dificuldade de conciliação com a rotina/tempo}

O público-alvo do Programa é predominantemente formado por estudantes entre as faixas inicial e intermediária da graduação, que, geralmente, possuem uma carga elevada de atividades relacionadas à sala de aula, como exercícios extraclasses, seminários e trabalhos. Além disso, muitas vezes, utilizam as horas vagas para se capacitarem com cursos ou treinamentos, comprometendo ainda mais seu tempo disponível, que, ainda, é dedicado à família e atividades sociais. Alguns trainees creditaram ao Programa a redução em seu nível de desempenho acadêmico, como no discurso "Com relação à universidade, me atrapalhou, porque eu não conseguia dar atenção às duas partes, e a partir daí eu tive dificuldade nas cadeiras, tirei algumas notas baixas, me atrapalhou um pouco" (TrI.16, informação verbal, grifo nosso) ou “Em relação à universidade, eu confesso que deixei um pouco de lado.” (TrXV.14, informação verbal, grifo nosso).

Os relatos dos ex-trainees I e XV colocam em cheque a contribuição da elevada carga de atividades imposta pelo Programa para a formação dos participantes. O crescimento dos participantes também está condicionado a aspectos que não se encontram dentro da esfera do Programa, como o desempenho acadêmico e as atividades 
sociais realizadas em grupo, o que, muitas vezes, parece ser esquecido pelos membros da EJA na condução do processo seletivo.

Pressionados para apresentarem resultados e pelas avaliações constantes, os participantes acabam por abrir mão do tempo destinado normalmente às outras obrigações para se dedicarem ao Programa, alterando, muitas vezes, sua rotina por completo, sem mensurar os prejuízos que essa decisão pode acarretar em longo prazo. Sobre a dificuldade na gestão do tempo, os trainees asseveram que "Pra mim, o que mais dificultou foi o horário, eu tinha que ficar direto, não podia ir pra casa, às vezes não almoçava [...] Então foi esse o sacrifício, mas no mais foi bom” (TrXV.12, informação verbal, grifo nosso) e “As etapas de trabalho são cansativas, sugam ao máximo as pessoas, e às vezes não pegam o melhor [...] Assim, chegam tão ao máximo, você está num estado tão avançado de cansaço e fadiga que às vezes você não consegue dar o melhor”. (TrII.4, informação verbal, grifo nosso).

É necessário que os organizadores do Programa avaliem os impactos que a demanda de atividades pode gerar na rotina dos participantes. Como já discutido em seções anteriores, uma experiência negativa em uma fase de maturidade tão precoce pode acarretar traumas para o resto da vida do participante. Um exemplo de situação extrema é relatado pelo trainee: "Eu tinha as madrugadas pra estudar e fazer as tarefas do trainee, o que me desgastou muito, inclusive em termos de saúde, porque não conseguia me alimentar direito, estava o tempo todo sob muita pressão.” (TrXIV.13, informação verbal, grifo nosso).

Essa postura, valorizada de forma equivocada pelos membros da EJA, é assumida por participantes com uma capacidade de discernimento limitada pela imaturidade e sem nenhum apoio psicológico para tal.

\subsubsection{Conflitos comportamentais e ideológicos}

Uma dificuldade recorrente identificada nas entrevistas foi a existência de conflitos comportamentais e ideológicos entre os trainees e a estrutura do Programa; problema comum, já que em alguns casos os trainees criam expectativas bem diferentes da realidade (TOLEDO; BULGACOV, 2004). Contudo, em vez de o Programa Trainee da EJA fomentar um ambiente favorável ao processo de transição, traz em sua estrutura elementos que geram atritos ideológicos com alguns participantes, que ainda não estão preparados para lidar com a realidade profissional.

Inicialmente, pode ser feito um paralelo da relação entre os conflitos e a perda de foco do participante no Programa, consequentemente, gerando baixos níveis de aprendizagem. Nos depoimentos, os trainees relatam que o tom agressivo dos parti- 
cipantes durante as aulas é visto de forma negativa. O participante que não concorda com essa postura acaba a repudiando. "Realmente em alguns momentos eu não concordei com a postura agressiva nas aulas. No momento que você tá fazendo o trainee é extremamente estressante.” (TrII.32, informação verbal, grifo nosso). Relatam, ainda, a falta de humildade de alguns membros em não reconhecer os erros, mesmo nas situações em que aparentemente estavam equivocados.

No discurso: "Em alguns momentos eu pensei em desistir do trainee [...] pelo comportamento da pessoa, pela forma como dava aula, e pela conduta em si” (TrVI.21, informação verbal, grifo nosso) evidencia-se que os conflitos de ideologia mal resolvidos podem também afastar bons talentos da EJA. Incomodados pela intransigência da empresa, alguns participantes passam a considerar o abandono e, nesse caso, as duas partes saem perdendo. Mais uma vez vêm à tona as discussões sobre os malefícios que os excessos podem trazer e, principalmente, as perdas que podem ser ocasionadas pela ausência de um canal de comunicação democrático entre os participantes e os membros da EJA.

Outro aspecto passível de discussão são os valores difundidos pelo Programa e sua influência na formação profissional dos participantes. Assim que são aprovados para o processo seletivo, os trainees são submetidos a uma política de avaliação baseada na realidade do mercado. Rapidamente são instruídos a formalizarem suas vestimentas, abandonarem hábitos considerados inadequados e modificarem sua rotina para que esta se baseie na vida profissional. Nessa política adotada e difundida pela empresa, o trabalho vem em primeiro lugar, exigindo, para isso, esforços como a diminuição de horas de sono e momentos de lazer, se necessário, sob a alegação de que "o mercado hoje em dia funciona dessa forma”. O discurso do trainee a seguir mostra muito bem essa realidade na qual “[...] às vezes você está sendo modificado de uma maneira alienada sem perceber.” (TrXI.33, informação verbal, grifo nosso). De fato, em nenhum momento do Programa se discute se essa postura é a mais adequada, ou mesmo se os valores que estão no alicerce são coerentes; simplesmente, é uma herança repassada ao longo das gerações e que pode se configurar como um processo de alienação prejudicial à capacidade de reflexão do jovem sobre a precarização existente no mercado de trabalho.

\subsubsection{Pressões do contexto social}

As pressões sociais dos diversos contextos nos quais os trainees estão inseridos, como família, círculos de amizade, universidade, entre outros, também são fatores que podem interferir negativamente no processo de aprendizagem, ainda que 
não estejam diretamente ao alcance da empresa júnior. Seja pelo senso natural de proteção, no caso das pessoas mais próximas, seja percepção dos professores nas situações de declínio acadêmico, os agentes sociais apresentam, de acordo com os relatos, uma resistência em relação à participação do jovem no Programa, que pode ser representada por opiniões negativas e desestímulos que, muitas vezes, interferem no desempenho.

As pressões também estão diretamente ligadas aos altos índices de desistência. Como fala o entrevistado (TrIV.16, informação verbal, grifo nosso): “Eu desisti de fazer o trainee na primeira semana justamente por causa dessas pressões [...] Eu poderia ter ficado pelo trainee, mas escolhi voltar, então significa que eu cedi a essas pressões”, as interferências externas foram tamanhas que o levaram a abrir mão de sua participação. Ele deixa claro que sua desistência ocorreu pelo fato de ter cedido às pressões do Programa. Acompanhamento psicológico e integração entre os agentes sociais podem ser boas alternativas para garantir que o foco do participante não seja comprometido.

\subsection{DISCUSSÃO DOS RESULTADOS}

Os resultados da pesquisa apontam que o processo de aprendizagem durante o Programa Trainee da EJA é influenciado por fatores facilitadores e limitantes, que interferem positiva ou negativamente na forma como os participantes assimilam o conhecimento transmitido nas aulas. Os fatores facilitadores mais incidentes nos discursos foram o relacionamento interpessoal, o nível de exigência e a estrutura de atividades baseada na aprendizagem em ação.

Por outro lado, os fatores que, de alguma forma, limitaram o desempenho dos entrevistados foram a dificuldade de conciliação com a rotina/tempo, os conflitos comportamentais e ideológicos e as pressões do contexto social. Com base nos resultados que emergiram do estudo, foi elaborado um quadro que sintetiza os fatores determinantes do processo de aprendizagem no Programa Trainee da EJA, o qual é apresentado a seguir:

Quadro 1 - Determinantes do processo de aprendizagem no Programa Trainee da EJA

\begin{tabular}{|l|l|l|}
\hline \multirow{2}{*}{ Fatores } & Caracterização & $\begin{array}{l}\text { Atributos que influenciam o processo de apren- } \\
\text { dizagem }\end{array}$ \\
\hline \multirow{3}{*}{ Facilitadores } & Relacionamento interpessoal & $\begin{array}{l}\text { Cooperação; tolerância; orientação para resul- } \\
\text { tados. }\end{array}$ \\
\cline { 2 - 3 } & Nível de exigência & Motivação; abnegação; amadurecimento \\
\cline { 2 - 3 } & Aprendizagem em ação & Experiência; know-why; know-how. \\
\hline
\end{tabular}




\begin{tabular}{|l|l|l|}
\hline \multirow{4}{*}{ Limitantes } & $\begin{array}{l}\text { Dificuldade de conciliação com a } \\
\text { rotina/tempo }\end{array}$ & $\begin{array}{l}\text { Falta de foco; comprometimento da atenção; } \\
\text { sobrecarga física/emocional. }\end{array}$ \\
\cline { 2 - 3 } & $\begin{array}{l}\text { Conflitos comportamentais e } \\
\text { ideológicos }\end{array}$ & Insatisfação; desmotivação; irritabilidade. \\
\cline { 2 - 3 } & Pressões do contexto social & $\begin{array}{l}\text { Instabilidade emocional; conflitos psicológicos; } \\
\text { desânimo. }\end{array}$ \\
\hline
\end{tabular}

Fonte: os autores.

Na primeira coluna se distinguem os fatores facilitadores (positivos) dos limitantes (negativos). Na segunda coluna, denominada de caracterização, elencam-se os determinantes que emergiram a partir da análise das entrevistas. Na coluna seguinte, são apresentados os atributos oriundos de cada determinante que exercem influência no processo de aprendizagem dos participantes do Programa.

Partindo dessa perspectiva e relacionando-a aos determinantes facilitadores do processo de aprendizagem, é evidente que, além da vontade propriamente dita de passar pelo processo e fazer parte da empresa, é fundamental que os participantes também possuam uma compatibilidade de perfil que esteja dentro das delimitações estabelecidas pela estrutura do Programa Trainee, além da própria atividade-fim em caso de efetivação: a consultoria organizacional.

Em relação aos fatores limitantes, evidencia-se o processo de sofrimento dos participantes, relatado por Toledo e Bulgacov (2004), iniciado durante o processo seletivo, no qual os trainees são submetidos a situações que geram consequências como insatisfação, desmotivação, irritabilidade e instabilidade emocional, aspectos que, inegavelmente, influenciam o seu desempenho e a forma como aprendem ao longo do processo. Em um contexto pautado pela tensão, não se pode esperar que a aprendizagem ocorra da forma ideal.

O quadro demonstra o quanto os participantes são vulneráveis aos estímulos do contexto social que os envolvem, tanto positivamente quanto negativamente, sobretudo, pela natural falta de maturidade dos jovens aspirantes. Diante desse cenário, faz-se necessário um melhor acompanhamento comportamental por parte da empresa júnior em relação aos trainees como forma de inibir os impactos traumáticos de uma possível experiência de frustração profissional (GONTIJO; MELO, 2005).

\section{CONCLUSÃO}

Na pesquisa objetivou-se analisar, a partir de uma abordagem qualitativa, o processo de aprendizagem em Programas Trainees, identificando-se os fatores facilitadores e limitadores da aprendizagem a partir de entrevistas realizadas com ex-parti- 
cipantes do Programa para compreender a forma como os jovens aprendem dentro do contexto no qual estão inseridos.

Os Programas Trainees têm sido utilizados pelas empresas como uma das principais ações para captação de talentos, com estruturas cada vez mais sólidas e condizentes com o competitivo mercado de trabalho atual. Em relação ao Programa Trainee da EJA, pode-se afirmar que ele contribui para a formação profissional dos alunos da UFPB, como canal de aprendizagem e elo entre a formação acadêmica e o mercado de trabalho. O reconhecimento, porém, ainda é insuficiente para as aspirações e pelo potencial que possui, principalmente, por parte das IES e dos órgãos públicos.

As conclusões iniciais evidenciam que, com base na análise estrutural do Programa Trainee da EJA, pode-se constatar que este está de acordo com o que é praticado no mercado, com etapas sequenciais bem definidas, nível de exigência acentuado e foco educacional baseado na aprendizagem em ação (GONTIJO; MELO, 2005; MARTINS, 2008). O Programa possui em sua estrutura fases de recrutamento, seleção, treinamento e desenvolvimento, avaliação, efetivação e integração. A realização de aulas com a finalidade de estimular o desenvolvimento de competências nos trainees também é recorrente no mercado. A busca pela simulação da realidade mercadológica é intencional e visa a melhor preparar os participantes para as situações que enfrentarão em caso de efetivação.

Entre as principais oportunidades de melhoria relacionadas à estrutura do Programa apontadas no estudo, destacam-se um maior monitoramento em relação à postura excessivamente rígida e à grande carga de tarefas, que acabam prejudicando o desempenho dos participantes em outras esferas, como a universidade e os círculos sociais. Como aspectos positivos, foram recorrentes opiniões elogiosas em relação à estrutura voltada para a prática, favorável a um ambiente voltado à aprendizagem (ZEFERINO; PASSERI, 2007).

Sobre os fatores que favorecem a aprendizagem, foi citado pelos entrevistados que as atividades baseadas na simulação e na ação são importantes para a assimilação de conhecimento ao longo do processo. Além disso, a empresa sempre prioriza o desenvolvimento de tarefas em equipe, ponto que também é destacado de forma positiva pelos participantes. Um aspecto interessante revelado pelos entrevistados foi que o nível de exigência, apesar de ser bastante criticado nas situações em que ocorrem excessos, é visto como fator motivador para o estímulo à aprendizagem, pois faz com que o padrão de atenção nas aulas seja mantido. Dessa forma, pode-se concluir que níveis de pressão e cobrança na dosagem correta são importantes para que os jovens possam manter o foco necessário dentro do Programa Trainee. 
Como aspectos limitadores da aprendizagem, a dificuldade de conciliação com a rotina/tempo, os conflitos comportamentais e ideológicos e as pressões do contexto social foram destacadas como os mais relevantes. Reduzir a carga de trabalho e limitar o número de atividades extraclasse podem ser alternativas para minimizar os impactos na rotina dos participantes. Além disso, apresentar uma estrutura mais maleável em sua abordagem certamente reduziria a rejeição ocasionada pelos conflitos ideológicos.

Apesar de as pressões do contexto serem indicadas na pesquisa como fatores limitantes do processo de aprendizagem, cabe a ressalva de que nem sempre os estímulos externos são negativos. Em algumas situações, os entrevistados relataram que o apoio da família, dos amigos e da própria Universidade foi fundamental para manter o equilíbrio ao longo do Programa. Assim, conclui-se que a influência do contexto social no processo de aprendizagem é uma realidade, ainda que não se possa classificar essa interferência como positiva ou negativa em um primeiro momento, sendo necessária uma análise mais específica do cenário de cada indivíduo para determinar até que ponto o contexto potencializa ou prejudica a forma como estes aprendem.

Em linhas gerais, pode-se afirmar que a experiência proporcionada pelas empresas juniores, assim como as atividades de extensão como um todo, contribuem para a formação acadêmica, pois oferecem um campo de integração ativo entre as instituições de ensino e o mercado de trabalho. Aliar teoria e prática é fundamental para o desenvolvimento profissional dos estudantes (SÁ; OLIVEIRA; HONÓRIO, 2005). Participar de uma empresa júnior e interagir com o Movimento de Empresas Juniores durante a graduação pode ser enriquecedor ao proporcionar amadurecimento pessoal e profissional, além de orientar os alunos em relação aos rumos futuros de suas carreiras. Por outro lado, é preciso prudência para que o aluno não coloque a vivência na empresa júnior em nível de importância superior a sua formação acadêmica, uma vez que a integração entre teoria e prática, quando bem articulada, é determinante na carreira do administrador.

\section{REFERÊNCIAS}

ANDRADE, A. R. O curso de Administração, a empresa júnior e a formação de consultores de organização. In: SIMPÓSIO DE EXCELÊNCIA EM GESTÃO E TECNOLOGIA, 6., 2009, Rio de Janeiro. Anais... Rio de Janeiro: SEGet, 2009.

ARAÚJO, M. V. P. et al. Os programas de trainee e o desenvolvimento das competências gerenciais em uma empresa varejista. In: SIMPÓSIO DE EXCELÊNCIA EM GeStÃo E TECNOLOGIA, 4., 2007, Resende. Anais... Petrolina: SEGet, 2007. 
ARAÚJO, M. V. P. Programa de trainee e desenvolvimento das competências gerenciais: um estudo em uma grande empresa varejista brasileira. 2004. Tese (Doutorado em Administração de Empresas)-Universidade Federal da Paraíba, João Pessoa, 2004.

BITENCOURT, C. C. A gestão de competências gerenciais e a contribuição da aprendizagem organizacional. In: ENCONTRO NACIONAL DOS PROGRAMAS DE PÓS-GRADUAÇÃO EM ADMINISTRAÇÃO, 26., 2002, Salvador. Anais... Salvador: ANPAD, 2002. CD-ROM.

BRASIL JÚNIOR. Conceitos do MEJ. Disponível em: < http://www.brasiljunior. org.br/historico.php>. Acesso em: 09 fev. 2010.

COSTA, V. P.; SILVA, A. B. O processo de aprendizagem e desenvolvimento de competências em programas trainees: um estudo brasileiro. In: ENCONTRO DE INICIAÇÃO CIENTÍfICA, 19., 2011, João Pessoa. Anais... João Pessoa, 2011.

FOX, S. From management education and development to the study of management learning. In: BURGOYNE, J.; REYNOLDS, M. (Org.). Management learning: integrating perspectives in theory and practice. London: Sage Publications, 1997.

GHERARDI, S.; NICOLINI, D.; ODELLA, F. Toward a social understanding of how people learn in organizations. Management Learning, v. 29, i. 3, p. 273-297, 1998.

GODOI, M. G. M. et al. A influência do programa de trainees na Aprendizagem Organizacional. In: SEMINÁRIOS EM ADMINISTRAÇÃO, 11., 2008, São Paulo. Anais... São Paulo: USP, 2008.

GONTIJO, M. C. L.; MELO, M. C. O. L. Encontros e desencontros ao longo do processo de socialização organizacional de profissionais contratados por meio de programas de trainees. In: ENCONTRO ANUAL DA ASSOCIAÇÃO NACIONAL DE PÓS-GRADUAÇÃO E PESQUISA EM ADMINISTRAÇÃO, 29., 2005, Brasília. Anais... Brasília, DF: ANPAD, 2005.

KIM, D. The link between individual and organizational learning. Sloan Management Review, fall, p. 37-50, Oct. 1993.

LAVE, J.; WENGER, E. Situated learning: legitimate peripheral participation. New York: Cambridge University Press, 1991. 
LE BOTERF, G. Desenvolvendo as competências dos profissionais. Porto Alegre: Artmed, 2003.

LUZ, R. Programas de estágio e de trainee: como montar e implantar. São Paulo: Ltr, 1999.

MORAES, L. V.; SILVA, M. A.; CUNHA, C. J. C. A. Aprendizagem gerencial: teoria e prática. RAE-eletrônica, v. 3, n. 1, jan./jun. 2004.

SÁ, M. A. D.; OLIVEIRA, R. C. R.; HONÓRIO, J. B. Integração em empresas juniores: é brincando que se aprende!. In: ENCONTRO NACIONAL DE PÓS-GRADUAÇÃO E PESQUISA EM ADMINISTRAÇÃO, 29., 2005, Brasília, DF. Anais... Brasília, DF: ANPAD, 2005.

SILVA, A. B. A fenomenologia como método de pesquisa em estudos organizacionais. In: GODOI, C. K.; BANDEIRA-DE-MELLO, R.; SILVA, A. B. (Org.). Pesquisa qualitativa em estudos organizacionais: paradigmas, estratégias e métodos. 2. ed. São Paulo: Saraiva, 2010.

SILVA, A. B. Como os gerentes aprendem? São Paulo: Saraiva, 2009.

TOLEDO, S; BULGACOV, Y. Cultura organizacional e identidade: implicações dos ritos de passagem na identidade de jovens executivos trainees em uma organização multinacional. In: ENCONTRO NACIONAL DE PÓS-GRADUAÇÃO E PESQUISA EM ADMINISTRAÇÃO, 28., 2004, Curitiba. Anais... Curitiba: ANPAD, 2004. 1 CD-ROM.

ZEFERINO, A. M. B.; PASSERI, S. M. R. R. Avaliação da aprendizagem do estudante. Cadernos da ABEM, v. 3, p. 39-43, 2007. 
Como citar este artigo:

\section{ABNT}

SILVA, Anielson Barbosa; COSTA, Vinicius Paiva; DIAS, Saulo Oliveira Monteiro. Determinantes do processo de aprendizagem no Programa Trainee da Empresa Júnior de Administração (EJA) da Universidade Federal da Paraíba (UFPB). RACE: Revista de Administração, Contabilidade e Economia, Joaçaba: Ed. Unoesc, v. 15, n. 1, p. 275-298, jan./abr. 2016. Disponível em: <http://editora.unoesc.edu.br/index. php/race>. Acesso em: dia/mês/ano.

\section{APA}

Silva, A. B., Costa, V. P., \& Dias, S. O. M. (2016). Determinantes do processo de aprendizagem no Programa Trainee da Empresa Júnior de Administração (EJA) da Universidade Federal da Paraíba (UFPB). RACE: Revista de Administração, Contabilidade e Economia, 15(1), 275-298. Recuperado em dia/mês/ano, de http://editora.unoesc.edu.br/index.php/race 
